\title{
The Functional Neuroanatomy of Tourette's Syndrome: An FDG-PET Study. II: Relationships between Regional Cerebral Metabolism and Associated Behavioral and Cognitive Features of the Illness
}

\author{
Allen R. Braun, M.D., Christopher Randolph, Ph.D., Brigitte Stoetter, M.D., \\ Erich Mohr, Ph.D., Christine Cox, Ph.D., Katalin Vladar, M.D., Roy Sexton, B.S., \\ Richard E. Carson, Ph.D., Peter Herscovitch, M.D., and Thomas N. Chase, M.D.
}

We analyzed F-18 fluoro-deoxysluose PET sians carried out in 18 drug-free patients with Tourette's syndrome (TS! in order to evaluate relationships between cerebral metabolism and complex cognitize and behavioral feature's commonly associated with this disorder. These features (obsessions and compulsions, impulsivity, coprolalia, self-injurious behavior, echophenomena, depression, and measures of attentional and itsuospatial dysfunction) were associated with signiticant increases in metabolic activity in the orbitofrontal cortices. Similar increases, although less robust, were observed in the putamen and, in the case of attentional and risuospatial measures, in the inferior portions of the insula. On the other hand, behavioral and cognitive features in'ere not associated with metabolic rates in other subcortical imidbrain, wentral

From the VSS, VSLB, NIDCD (ARB), the 1 : $[B, N I N D S$ (BS, INC) and the PET department (REC, ['H), National Institutes of Health Bethesda, Maryland; the departments of Neurology and Psychiatr (CR), Northwestern University School of Medicine, Chicago, Illinoin the Institute of Mental Health Research (EM). University of Ottan a Canada; the Kennedy Krieger Institute (C) Baltimore, Maryland and the CBDB, NIMH Neuroscience ('enter at St. Elizabeths $\mid K I$ RS), Washington, DC.

The 1993 part I Braun et al. articte appeared in the $9(4)$ issue of Neit rops.fchopharmacology as pages 277.291 (see complete reference). and as of October 1995, the part III manuscript is in preparation

Address correspondence to Dr. Allen R. Braun. NIDCD. NIH. Build ing 10, Room 5D-38, Bethesda. MD 201892

Received June 20, 1994; revined March 1. 1945, actepted March h 199 亏. striatum), paralimbic (parahippocampal gyrus), or sensorimotor regions (supplementary motor area, lateral premotor or Rolandic cortices), in which metabolism had, in some cases more robustly, distinguished these TS patients from controls (Braun et al., 1993). These results suggest that a subset of regions in which metabolic activity appears to be associated with the diagnosis of TS per se, may be explicitly associated with the emergence of complex behavioral and cognitive features of the illness.

This is most conspicuous in the orbitofrontal cortices, and it is consistent with the observation that these features resemble the elements of a behavioral syndrome typically seen in patients with lesions of the orbitofrontal cortex. [Neuropsychopharmacology 13:151-168, 1995]

KH Y WORDS: Tourette's (Tourette) syndrome; Positron 'minsion tomography; FDG; obsessive-compulsive disorder; Impulsivity; Self-injurious behavior; Depression; Coprolalia; Echophenomena; Attention; Visuospatial: Orbitofrontal cortex; Insula; Basal ganglia

Since the disorder was initially described (Gilles de la Tourette 1885), it has been clear that the spectrum of symptoms in Tourette's syndrome (TS) includes complex neurobehavioral and cognitive disturbances in addition to simple vocal and motor tics. These symptoms include obsessions and compulsions, impulsivity, self- 
injurious behavior, echophenomena (echolalia, palilalia, echopraxia), attentional disturbances that may be associated with hyperactivity, complex, socially disruptive tics (such as coprolalia), and mood lability (Comings and Comings 1988; Riddle et al., 1988; Towbin, 1988). In addition, patients may experience anxiety, sleep disturbances, learning disabilities, and secondary behavioral problems such as social isolation (Glaze et al., 1983; Hagin and Kugler, 1988; Silver, 1988).

The anatomical substrate of motor symptoms in TS is poorly understood. The pathophysiology of the associated behavioral features is even more obscure. The initial results of our FDG-PET study (Braun et al. 1993) suggested that the TS brain may be characterized by lower metabolic rates in the inferior, limbic-related regions of the cortex and striatum, and in the midbrain, and higher metabolic rates in the superior, sensorimotor cortices. This may represent a metabolic pattern associated with the diagnosis of TS per se. Which of these regions might participate in the generation of the behavioral and cognitive symptoms is not clear. However, our patient group was heterogeneous, possessing a wide enough dynamic range of behavioral and cognitive features to make it possible to address this question.

We therefore used clinical, neuropsychological and FDG-PET data to identify patterns of regional activity that might be associated with specific neurobehavioral and cognitive symptoms in TS. The identification of functional neuroanatomical patterns that correspond to the various phenotypic expressions of this unusually heterogeneous disorder might suggest further avenues of research that could potentially lead to successful treatment.

\section{METHODS}

\section{Subjects}

Eighteen TS patients, 16 males and 2 females age $33 \pm$ 7 years (mean $\pm S D$; range $23-49$ years) consented to participate in this study after providing informed consent. Sixteen patients were right-handed, and two, one male and one female, were left-handed.

The subjects included the same cohort of 16 patients analyzed in our previous report as well as two patients from whom blood samples were not taken. These subjects were included in the present analysis because only normalized metabolic rates were evaluated.

The diagnosis of TS was confirmed by history and physical examination that excluded concurrent medical or other neurological or psychiatric illnesses and conformed to DSM-IV criteria. All patients were drug free at the time of scanning, medications having been withdrawn at least 2 weeks prior to the study (Braun et al. 1993).

\section{PET Scans}

PET scans were performed on the NeuroPET (Brooks et al. 1980), a seven-slice positron tomograph with an in-plane resolution of 6 to $7 \mathrm{~mm}$ and an axial resolution of 11 to $12 \mathrm{~mm}$ FWHM, according to a protocol described previously (Braun et al. 1993). Five mCi of FDG were injected intravenously over a period of 1 minute, and 10-minute scans were initiated 30 to 45 minutes after infusion. Between each scan, the position of the patient's head was shifted slightly within the gantry to increase the anatomical sampling by obtaining interleaved image sets. A calculated attenuation correction was performed using a visually fitted outline of the scalp. The scanner and gamma well counter were crosscalibrated using a phantom containing a solution of [F-18] fluoride. Local cerebral metabolic rates for glucose were calculated according to the method of Brooks (1982). Patients were asked to remain still during the course of the procedure. Although they were not explicitly instructed to suppress symptoms, vocal or motor tics were rarely observed during the period of FDG uptake.

\section{Image Analysis}

Eight image planes were selected for analysis on the basis of recognizable cerebral landmarks identified in standard anatomical atlases (Damasio and Damasio 1989; Duvernoy 1991; Matsui and Hirano 1989). Image planes were parallel to the canthomeatal line and extended from the level of the cerebellum, temporal pole, and gyrus rectus inferiorly to the superior frontoparietal convexities. In our earlier report, two separate analyses, each based on a different technical strategy, were performed, and these provided essentially convergent results. For this reason, only regional values derived using one of these methods were utilized in the present study. Irregular regions of interest were identified in the cortex using thresholding and edge-detection techniques; circular regions of interest (ROIs) were applied to subcortical structures and cortical regions in which anatomical detail was less precise, and data reduction was performed in these instances as previously described (Braun et al. 1993).

In our initial report, the results of both independent analyses showed the highest degree of convergence when metabolic rates were normalized, controlling for intersubject differences in CMRglu and thereby reducing group variances. For this reason, normalized values were utilized in the present analysis. Regional metabolic rates were divided by global metabolic rates; global rates were estimated by averaging all regional grey matter metabolic rates, weighting these for the area enclosed within each ROI. For the analyses summarized in Tables 3-6, normalized regional values were further 
reduced by averaging metabolic rates in functionally related ROIs (e.g., medial orbital cortex contained in planes 2 and 3), again weighting these for the area enclosed within each region.

\section{Clinical Evaluation}

Within 1 week of PET scanning, all patients underwent a formal neurological evaluation that included a physical examination, structured historical interview, and review of medical records. Data provided by referring physicians as well as old records, in some cases from prior admissions to the NIH Clinical Center, were reviewed.

Standardized checklists were used to categorize patients with respect to the historical presence or absence of six common behavioral features (Table 1). Because of the waxing and waning of behavioral as well as motor symptoms in TS, the historical prevalence of complex behavioral features was considered, whether or not symptoms were present at the time of evaluation. Behavioral features and their associated criteria in cluded:

1. Obsessive-compulsive symptoms (recurrent, intrusive thoughts, ideas, or images; repetitive ritualistic behaviors, performed intentionally; symptoms may or may not have been distressful; symptoms may have been intermittent but must have occurred over the course of at least 1 year, and when present lasted more than 1 hour a dav).

2. Echophenomena (nonstuttered repetition of one's own syllables, words, or phrases (palilalia) or those of another individual (echolalia) and/or voluntary imitation of another individual's motor behavior (echopraxia); symptoms may have been intermittent but must have occurred over the course of at least 1 year and, when present, accurred several times a day).

3. Coprolalia (inappropriate or obscene svllables. words, or phrases often expressed explosively; these complex vocal tics may be characterized by tic substitution and may wax and wane but must have occurred over the course of at least 1 year and, when present, occurred several times a dav).

4. Impulsivity (episodic failure to inhibit aggressive or sexual impulses directed at others; socially inappropriate verbal or overt behaviors, frequently unprovoked, must have occurred over the course of at least 1 year).

5. Self-injurious behavior (harmful self-directed behaviors-e.g., episodic punching, biting, risk-taking behavior that has resulted in injury - must have occurred over the course of at least 1 vear).
6. Depression (significantly depressed mood without psychotic features lasting at least 2 weeks, which may have represented a dysphoric response to neuroleptic medications).

Although the criteria for depression and obsessivecompul: ive behaviors do not strictly conform to DSM IV criteria, they identify several behavioral features, such as dysphoric response to medications, obsessive or compulsive symptoms that do not cause distress, that are frequently seen in TS patients. Attentional parameters were not evaluated in this portion of the study because they were measured directly in the neuropsychological assessment described later.

Patients typically displayed more than one associated symptom and were assigned to a number of different categories. Therefore, patients were ranked according to complexity of clinical presentation, both to unify the analysis and to expand the dynamic range. Each subject received a summary score of 0 to 6 (the behavioral or "complex symptom" score), depending on the number of behavioral features present (Table 1 ). In general, the patients' records indicated that those with higher symptom scores had a more difficult clinical course and a more erratic response to treatment.

Categorical variables were developed using these scores for use in some of the statistical tests outlined later. Each patient was assigned to one of three categories reflecting the degree of behavioral severity. These were designed to provide more or less equal numbers of subjects in each category ("high" $=3-6$ symptoms, $n=5 ;$ "medium" $=2$ symptoms, $n=7$; "low" $=0-1$ simptom, $n=6$ ).

\section{Neuropsychological Tests}

Fifteen of the TS patients were given a variety of standardized and experimental neuropsychological tests within 1 week of PET scanning. All test scores were transformed to standardized $z$-scores. Verbal and Performance IQ scores derived from the WAIS-R (Wechsler 1981) were evaluated independently.

In order to reduce the number of variables for anal$v$ sis and permit the independent evaluation of distinct neuropsychological functions, tests were grouped by neuropsychological domain. Categories included: attention, visuospatial-constructional, memory, and executive functions. For each neuropsychological factor, a summary score was derived for each subject by computing a mean from the $z$-scores of the constituent tests:

\section{Atte'ntion}

Letter cancellation test (Lezak 1983)

Simple and complex reaction time (Luria 1973)

Digit span (WAIS-R)

Digit symbol (WAIS-R) 
Table 1. Frequency of Individual Symptoms in Tourette's Patients with Low, Medium, and High Behavioral Severity Scores

\begin{tabular}{lccc}
\hline Symptom & \multicolumn{3}{c}{ Category (Total Symptoms) } \\
\cline { 2 - 4 } & $\begin{array}{c}\text { Low [0-1] } \\
(\boldsymbol{n}=\mathbf{6})\end{array}$ & $\begin{array}{c}\text { Medium [2] } \\
(\boldsymbol{n}=\mathbf{7})\end{array}$ & $\begin{array}{c}\text { High [3-6] } \\
(\boldsymbol{n}=\mathbf{5})\end{array}$ \\
\hline Self-injurious behavior & 0.00 & 0.14 & 0.40 \\
Impulsivity & 0.00 & 0.14 & 0.60 \\
Echophenomena & 0.00 & 0.00 & 0.80 \\
Coprolalia & 0.17 & 0.43 & 0.40 \\
Obsessive-compulsive behavior & 0.17 & 0.71 & 1.00 \\
Depression & 0.33 & 0.57 & 0.60 \\
\hline
\end{tabular}

2. Visuospatial/constructional

Embedded figures test (Witkin 1950)

Manikin test (Ratcliff 1979)

Mosaic test (Fedio et al. 1979)

Copy score, Rey complex figure (Rev 1941; Osterreith 1944)

Street map test (Money, 1976)

Object assembly (WAIS-R)

Block design (WAIS-R)

3. Memory

Delayed free recall, Rey complex figure

Total recall (trials 1-5), Rey auditory verbal learning test (Rey 1986)

Delayed free recall, Rey auditory verbal learning test

Wechsler memory scale (Wechsler and Sidne 1945)

4. Executive function

Verbal fluency (FAS) (Benton and Hamsher 1976)

Categories, Wisconsin card sorting test (Heaton 1981)

Percent perseverative errors, Wisconsin card sorting test

For purposes of comparison, the summary scores for these four parameters were reversed in sign (multiplied by -1 ) so that higher scores would represent indices of attentional, visuospatial, memory, and executive dv'sfunction.

\section{Statistical Analysis}

Two general approaches were undertaken in evaluating the behavioral and neuropsychological characteristics of this group of TS patients. In the first approach, subjects were categorized with respect to behavioral and neuropsychological features, and the relationships between these features and regional glucose metabolic rates were evaluated. Normalized metabolic rates were first analyzed by univariate repeated measures analy- ses of variance, with the complexity of behavioral symptoms (high, medium, and low categories) representing the grouping (between) factor and regions of interest the repeated (within) measures. The relationship between complexity of behavioral presentation and regional metabolic activity was further defined by correlating the (discrete) behavioral scores themselves with normalized rCMRglu values using nonparametric techniques (Kendall's rank correlation). Relationships between (continuous) standardized scores of neuropsychological performance and normalized rCMRglu were characterized using parametric techniques (Pearson product-moment correlations). A binomial probability statistic was used to calculate whether the number of observed correlations exceeded that expected by chance. Pearson product-moment correlations were also calculated between metabolic rates in the limited set of regions which had differentiated patients and normals in the initial portion of our study.

In the second approach, the regional metabolic rates were used to divide the patients into "metabolic" subgroups using Q-component analysis (Clark et al. 1985; Gorusch 1974; Grady et al. 1990): The data matrix of normalized regional metabolic rates for TS patients was transposed and a principal components analysis performed; an oblique rotation was then applied to the factor matrix in order to maximize differences between subgroups. Designed to identify different patterns of regional metabolism across patients, this technique permits substantial data reduction by considering all ROIs simultaneously. Because the degree of pattern similarity can be assessed across individual subjects, the technique can be used to determine whether or not a clinical sample is homogeneous with respect to regional cerebral metabolism and to identify distinct subtypes within a heterogeneous population. Subtypes that were identified in this fashion (i.e., on the basis of regional metabolic data alone) were then compared with respect to clinical presentation and neuropsychological performance using the statistical techniques described. 
Table 2. Analysis of Variance: Regional Metabolic Rates in Tourette's Patients with Different Frequencies of Complex Behavioral Symptoms ${ }^{a}$

\begin{tabular}{lrcrc}
\hline & \multicolumn{4}{c}{ Analysis 1 } \\
\cline { 2 - 5 } Source & $\mathbf{d f}$ & SS & $f$ test & $p$ Value \\
\hline Behavioral category & 2 & 0.033 & 2.34 & NS \\
Region of interest & 163 & 35.11 & 32.05 & $p=.0001$ \\
Region $\times$ category & 326 & 2.636 & 1.20 & $p=.01$ \\
\hline
\end{tabular}

${ }^{a}$ Grouping factor: behavioral complexity; repeated measures: normalized regional metabolic rates.

\section{RESULTS}

\section{Neurobehavioral Symptoms}

Complex symptom scores were calculated for each subject, and subjects were assigned to categories (low, medium, and high) as outlined. The distribution of individual behavioral symptoms was homogeneous within each category (i.e., no single symptom dominated chi squares were insignificant in each case), and the frequency of each symptom increased systematically as overall complexity increased, that is, the more symptoms a patient had, the more likely he or she was to have a history of any one of the six behavioral features (Table 1).

A repeated measures analysis of variance, in which behavioral complexity (high, medium, and low frequency categories) served as the grouping factor and ROIs as the repeated measures, yielded a significant complexity by region interaction term $(p<.01)$, indicating that TS patients with differing clinical presentations (i.e., differing frequencies of associated neurobehavior- al symptoms) can be distinguished by differences in metabolic activity in specific regions of the brain (Table 2).

These regions were identified by correlating complex behavioral scores and regional glucose metabolic rates. Table 3 summarizes correlations between complex symptom scores and metabolic rates in the limited set of regions that significantly differentiated TS patients and controls in our previous report (Braun et al. 1993). These are represented as $z$-scores derived from the nonparametric Kendall correlation analysis. Figure 1 depicts these relationships throughout the brain (regional data are not reduced in this case; Figure 2 serves as a legend). In either instance (i.e., when the analysis is restricted to the limited set of comparisons, or when the whole brain is evaluated) the binomial probability statistic indicates that the number of significant correlations exceeds that expected by chance (in the limited set of comparisons, $z=7.83, p<.00001$; in the brain as a whole, $z=4.59, p<.00001$ ).

These results indicate that patients with a more complicated neurobehavioral presentation are characterized by relative increases in metabolic activity in the orbitofrontal cortices bilaterally. Metabolic rates in other regions that had distinguished TS patients from normals, including the midbrain, ventral striatum, inferior insular cortex, parahippocampal gyrus, and sensorimotor (premotor and Rolandic) cortices, did not appear to vary with symptom complexity. However, metabolic rates in the putamen, like the orbital cortices, were positively correlated with scores of behavioral complexity in both left and right hemispheres.

Correlations between metabolic rates themselves were generated for the limited set of regions that had differentiated patients and normals in the initial por-

Table 3. Correlations between Regional Glucose Metabolic Rates and Measures of Behavioral Complexity

\begin{tabular}{|c|c|c|}
\hline \multirow[b]{2}{*}{ Region of Interest } & \multicolumn{2}{|c|}{ Kendall Z } \\
\hline & Left Hemisphere & Right Hemisphere \\
\hline \multicolumn{3}{|l|}{ Subcortical } \\
\hline Midbrain & 1.54 & 1.37 \\
\hline Ventral striatum & 0.68 & 1.75 \\
\hline Putamen & $2.00^{a}$ & $1.96^{a}$ \\
\hline \multicolumn{3}{|l|}{ Limbic cortical } \\
\hline Medial orbital cortex & $2.74^{b}$ & $3.19^{d}$ \\
\hline Lateral orbital cortex & $2.77^{\circ}$ & $2.64^{h}$ \\
\hline Opercular orbital cortex & $2.67^{b}$ & $2.17^{a}$ \\
\hline Caudal orbital cortex & $1.96^{a}$ & $2.03^{a}$ \\
\hline Inferior insula & 0.72 & 1.32 \\
\hline Parahippocampal region & 0.04 & -1.20 \\
\hline \multicolumn{3}{|l|}{ Frontal motor } \\
\hline Lateral premotor cortex & 0.38 & 0.72 \\
\hline SMA & 0.93 & 0.11 \\
\hline Inferior rolandic cortex & -0.17 & -0.38 \\
\hline Superior rolandic cortex & -0.81 & 0.13 \\
\hline
\end{tabular}

${ }^{a} p<.05 ;{ }^{b} p<.025 ; " p<.01 ;{ }^{d} p<.001$. 


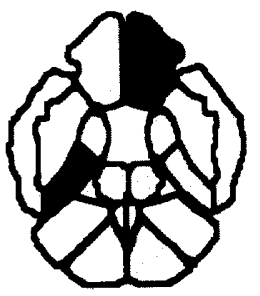

Slice 1

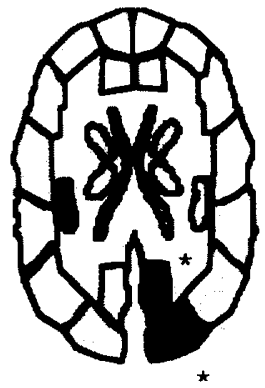

Slice 5

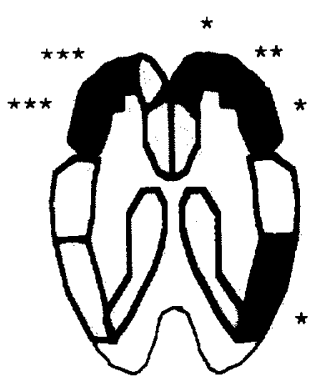

Slice 2

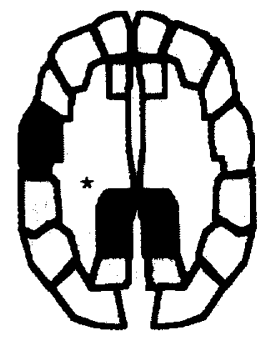

Slice 6

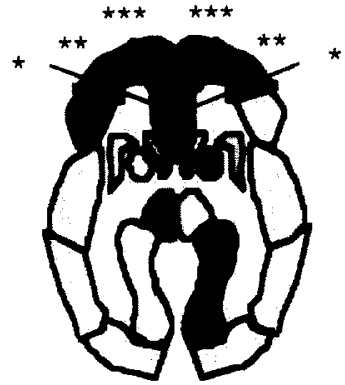

Slice 3

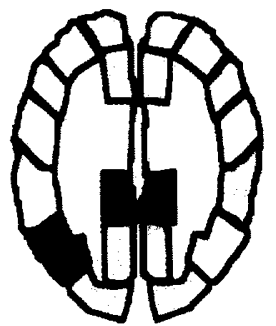

Slice 7

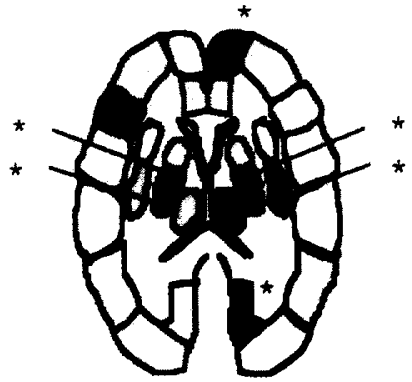

Slice 4

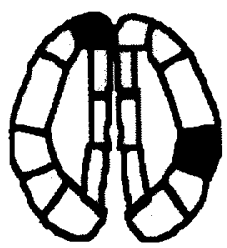

Slice 8

Figure 1. An anatomical representation of correlations between regional metabolic rates and complex symptom scores in Tourette's patients. Red indicates a positive correlation between these values (i.e., higher regional metabolic rates associated with higher indices of behavioral severity); blue indicates a negative correlation. The magnitude of the correlations is indicated by the degree of stippling: Absolute Kendall rank correlation $z$-scores above 2 are represented by solid colors; scores between 1.5 and 2 by dense stippling; between 1.0 and 1.5 by moderate stippling; between 0.5 and 1 by light stippling; regions with scores below 0.5 are uncolored. Significant correlations are indicated by asterisks: ${ }^{\star} p<.05,{ }^{\star \star} p<.01$,

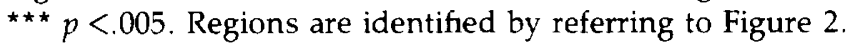

tion of our study. Metabolic rates in both the left and right putamen were significantly correlated with rates in the left and right caudal and medial orbitofrontal cortices $(p<.01$, in each case), but not with metabolic rates in other regions of interest).

When any of the six behavioral symptoms was evaluated independently, the same general patterns persisted. Individual symptoms were treated as dichotomous variables, and metabolic rates in subjects in whom a behavioral symptom was present were compared with rates in subjects in whom that symptom was absent. The presence of each behavioral symptom was associated with increased orbitofrontal metabolic rates for glucose. No single behavioral measure appeared to inordinately "drive" the relationships between orbitofrontal activity and complex symptom scores.

\section{Neuropsychological Function}

The group as a whole was characterized by average to above-average intelligence (WAIS- $R$ full scale IQ = $110 \pm 15$ ). Verbal IQ and Performance IQ evaluated separately were both within average range and were both associated with a similar degree of intersubject variability (VIQ $=111 \pm 16 ; \mathrm{PIQ}=107 \pm 15)$. The relationships between verbal and performance IQ and cerebral metabolism were evaluated by independently correlating these scores with regional metabolic rates for glucose in the limited set of regions that had previously distinguished TS patients and controls (Braun et al. 1993).

In almost every instance, significant correlations were observed between glucose metabolic rates and performance rather than verbal IQ scores (Table 4). These were more frequent, and more robust, in the right hemisphere and, as with behavioral severity scores, were clustered in the orbitofrontal cortices. These relationships were uniformly inverse (i.e., the lower the performance IQ, the higher the orbital metabolic rates). In addition, performance IQ was inversely correlated with metabolic activity in the functionally related inferior insular cortex of the right hemisphere. Unlike the behavioral severity scores, there was no apparent relationship between either IQ score and metabolic rates in the putamen.

The performance IQ score on the WAIS-R is often considered a rough measure of right hemisphere function (Kolb and Whishaw 1990; Wechsler 1958). How- 


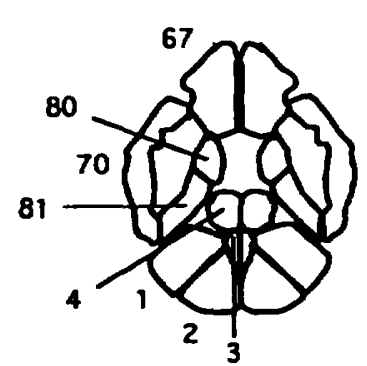

Slice 1

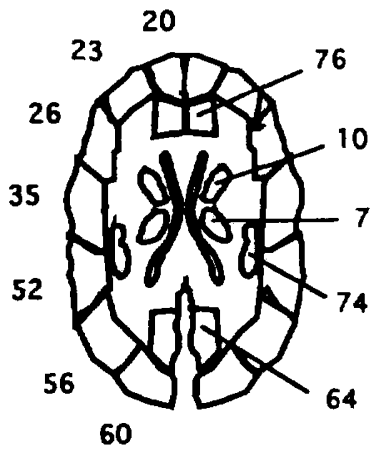

Slice 5

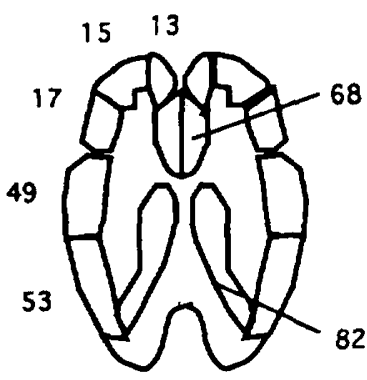

Slice 2

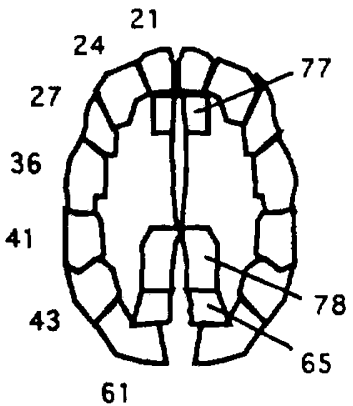

Slice 6

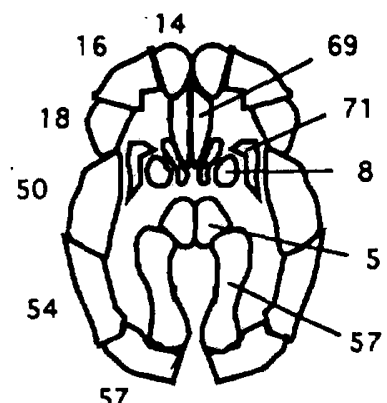

Slice 3

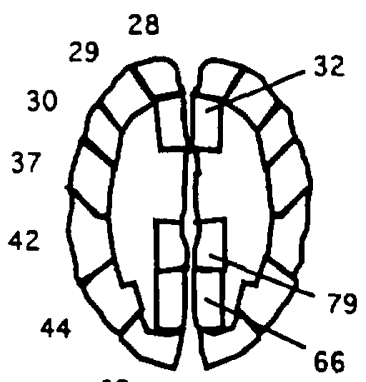

62

Slice 7

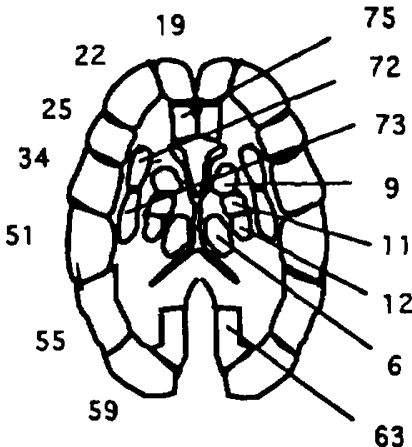

Slice 4

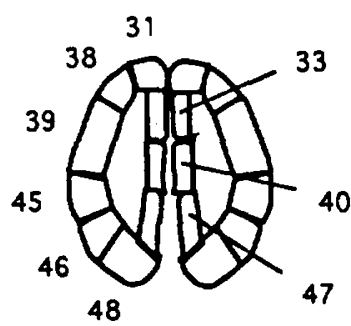

Slice 8

Legend: Regions of Interest

$\begin{array}{ll}\text { Cerebellum } \\ 1 & \text { Lateral cerebellum } \\ 2 & \text { Medial cerebellum } \\ 3 & \text { Cerebellar vermis } \\ \text { Brainstem } \\ 4 & \text { Pons } \\ 5 & \text { Midbrain } \\ \text { Thalamus } \\ 6 \text { Ventral thalamus } \\ 7 & \text { Dorsal thalamus } \\ \text { Basal ganglia } \\ 8 \text { Ventral striatum } \\ 9 \text { Head, caudate } \\ 10 & \text { Body, caudate } \\ 11 & \text { Anterior putamen } \\ 12 & \text { Posterior putamen } \\ \text { Prefrontal cortex } \\ 13 & \text { Medial orbital cortex } 1 \\ 14 & \text { Medial orbital cortex } 2 \\ 15 & \text { Lateral orbital cortex } 1 \\ 16 & \text { Lateral orbital cortex } 2 \\ 17 & \text { Opercular orbital cortex } 1 \\ 18 & \text { Opercular orbital cortex } 2 \\ 19 & \text { Inf med prefrontal cortex } \\ 20 & \text { Mid med prefrontal cortex } \\ 21 & \text { Sup med prefrontal cortex } \\ 22 & \text { Inf lat prefrontal cortex } \\ 23 & \text { Mid lat prefrontal cortex } \\ 24 & \text { Sup lat prefrontal cortex } \\ 25 & \text { Inf frontal opercular cortex } \\ 26 & \text { Mid frontal opercular cortex } \\ 27 & \text { Sup frontal opercular cortex } \\ \end{array}$

\begin{tabular}{|c|c|}
\hline \multirow{2}{*}{\multicolumn{2}{|c|}{ Frontal motor cortex }} \\
\hline & \\
\hline 28 & Inf lat premotor cortex 1 \\
\hline 29 & Inf lat premotor cortex 2 \\
\hline 30 & Inf lat premotor cortex 3 \\
\hline 31 & Sup lat premotor cortex \\
\hline 32 & Anterior sma \\
\hline 33 & Posterior sma \\
\hline 34 & Inf rolandic cortex 1 \\
\hline 35 & Inf rolandic cortex 2 \\
\hline 36 & Inf rolandic cortex 3 \\
\hline 37 & Sup rolandic cortex 1 \\
\hline 38 & Sup rolandic cortex 2 \\
\hline 39 & Sup rolandic cortex 3 \\
\hline 40 & Paracentral lobule \\
\hline \multicolumn{2}{|c|}{ Parietal cortex } \\
\hline 41 & Supramarginal gyrus 1 \\
\hline 42 & Supramarginal gyrus 2 \\
\hline 43 & Angular gyrus 1 \\
\hline 44 & Angular gyrus 2 \\
\hline 45 & Ant lat superior parietal lobule \\
\hline 46 & Post lat superior parietal lobule \\
\hline 47 & Ant med superior parietal lobule \\
\hline 48 & Post med superior parietal lobule \\
\hline \multicolumn{2}{|c|}{ Temporal cortex } \\
\hline 49 & Anterior superior temporal cortex 1 \\
\hline 50 & Anterior superior temporal cortex 2 \\
\hline 51 & Posterior superior temporal cortex 1 \\
\hline 52 & Posterior superior temporal cortex 2 \\
\hline 53 & Anterior inferior temporal cortex 1 \\
\hline 54 & Anterior inferior temporal cortex 2 \\
\hline 55 & Anterior inferior temporal cortex 1 \\
\hline 56 & Posterior inferior temporal cortex 2 \\
\hline
\end{tabular}

Occipital cortex

57 Fusiform (occipitotemporal) gyrus

58 Inf lat occipital cortex 1

59 Inf lat occiptal cortex 2

60 Mid lat occiptal cortex

61 Sup lat occiptal cortex 1

62 Sup lat occiptal cortex 2

63 inf calcarine cortex 1

64 Inf calcarine cortex 2

65 Sup calcarine cortex 1

66 Sup calcarine cortex 2

Paleocortical limbic

67 Gyrus rectus

68 Caudal orbital cortex 1

69 Caudal orbital cortex 2

70 Temporal polar cortex

71 Inferior insula

72 Anterior insula

73 Posterior insula

74 Superior insula

Archicortical limbic

75 Inf anterior cingulate

76 Mid anterior cingulate

77 Sup anterior cingulate

78 Inf posterior cingulate

79 Sup posterior cingulate

80 Amygdala-hippocampus

81 Parahippoc. Gyrus - hippocampus 1

82 Parahippoc. Gyrus-hippocampus 2

Figure 2. A representation of the regions of interest derived for the eight PET planes of section (see Figures 1 and 3 ). Numbers refer to the categorical list of region names contained in the legend. 
Table 4. Correlations between Regional Metabolic Rates and Verbal and Performance IQ Scores (WAIS-R)

\begin{tabular}{|c|c|c|c|c|}
\hline \multirow[b]{2}{*}{ Region of Interest } & \multicolumn{2}{|c|}{ Verbal IQ } & \multicolumn{2}{|c|}{ Performance IQ } \\
\hline & Left Hemisphere & Right Hemisphere & Left Hemisphere & Right Hemisphere \\
\hline \multicolumn{5}{|l|}{ Subcortical } \\
\hline Midbrain & -0.42 & -0.40 & -0.26 & -0.37 \\
\hline Ventral striatum & 0.32 & 0.21 & -0.26 & -0.37 \\
\hline Putamen & -0.21 & -0.05 & -0.03 & 0.03 \\
\hline \multicolumn{5}{|l|}{ Limbic cortical } \\
\hline Medial orbital cortex & -0.39 & -0.34 & $-0.62^{b}$ & $-0.58^{b}$ \\
\hline Lateral orbital cortex & -0.05 & -0.32 & -0.31 & $-0.57^{b}$ \\
\hline Opercular orbital cortex & -0.31 & $-0.64^{b}$ & $-0.60^{b}$ & $-0.77^{d}$ \\
\hline Caudal orbital cortex & -0.27 & $-0.54^{a}$ & $-0.52^{a}$ & $-0.68^{c}$ \\
\hline Inferior insula & -0.07 & -0.49 & -0.36 & $-0.52^{a}$ \\
\hline Parahippocampal region & -0.01 & -0.18 & 0.22 & 0.02 \\
\hline \multicolumn{5}{|l|}{ Frontal motor } \\
\hline Lateral premotor cortex & 0.23 & 0.30 & 0.01 & -0.05 \\
\hline SMA & -0.04 & 0.06 & -0.01 & 0.06 \\
\hline Inferior rolandic cortex & -0.07 & -0.38 & -0.01 & -0.41 \\
\hline Superior rolandic cortex & -0.16 & -0.15 & -0.21 & -0.36 \\
\hline
\end{tabular}

${ }^{a} p<.05 ;{ }^{b} p<.025 ;{ }^{c} p<.01 ;{ }^{d} p<.001$.

ever, it is derived from a heterogeneous series of subtests that, as a whole, may be sensitive to changes in attentional and visuospatial performance as well as variations in short-term visual memory. In order to evaluate relationships between cerebral metabolic activity and functionally discrete neuropsychological variables, the summary scores for attentional, visuospatial, memory, and executive performance were independently correlated with regional metabolic rates for glucose.

In only two instances, attention and visuospatial performance, did the numbers of significant correlations exceed those expected by chance alone. Correlations between metabolic activity and attention were signifcantly more frequent and more robust than correlations between metabolism and visuospatial performance. This difference is evident when $z$-scores derived from the binomial probability statistic were compared $(z=$ 6.93, $p<.00001$ for attention; $z=2.43, p<.01$ for visuospatial performance, in the limited set of regions that had distinguished TS patients and controls). Although formal bootstrap procedures were not employed in evaluating the correlations, visual inspection of each scattergram failed to detect the presence of outlying values spuriously augmenting the correlation coefficients (a potential problem with parametric comparisons that was not relevant to the nonparametric correlations reported).

As was the case with both complex behavioral scores and performance IQ, significant correlations between attention and metabolic activity clustered in the orbitofrontal cortices but were absent in the midbrain, ventral striatum, parahippocampal gyrus, and sensorimotor cortices (Table 5). As with performance IQ, attentional scores were significantly correlated with metabolic rates in the inferior insular cortex, and significant correlations with both orbitofrontal and insular metabolic activity were more robust in the right hemisphere. The correlations were in this case uniformly positive, since scores were calculated to reflect attentional dysfunction (i.e., the poorer the measures of attentional function, the higher the metabolic rates in these ROIs). As was the case with measures of behavioral severity, attentional scores were positively correlated with metabolic rates in the left putamen.

Figure 3 illustrates the relationships between attentional scores and regional metabolic rates throughout the brain. The number of significant correlations again exceeds that expected by chance $(z=6.09, p<.00001)$. A marked degree of convergence is apparent when this map is compared with Figure 1. The relationships between measures of attention and the independently derived scores of behavioral complexity both pinpoint the same general regions of interest, the orbitofrontal cortices, in which significant correlations are more frequent and are associated with the lowest probabilities of error.

Unlike the measures of behavioral severity, however, attentional dysfunction appears to be additionally associated with increases in dorsolateral prefrontal cortical metabolism and concommitant decreases in metabolic activity in visual association cortices. Significant relationships between measures of visuospatial dysfunction and regional metabolic rates (not illustrated) exhibited the same general anatomical distribution but were considerably less robust.

\section{Q-Component Analysis}

Regional metabolic values were normally distributed for each subject $(p>.05$ using the Kolmogrov-Smirnov test of normality). The data matrix of normalized meta- 


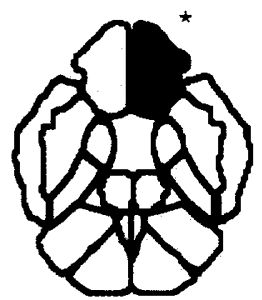

Slice 1

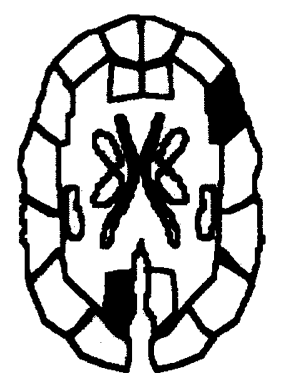

Slice 5

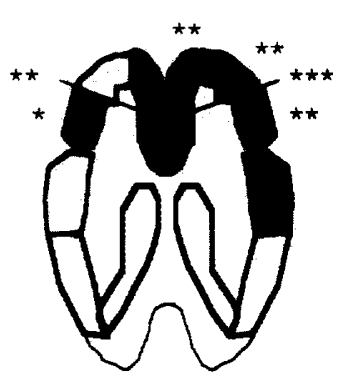

Slice 2

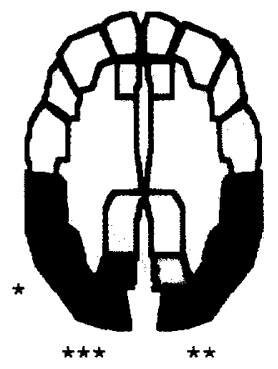

Slice 6

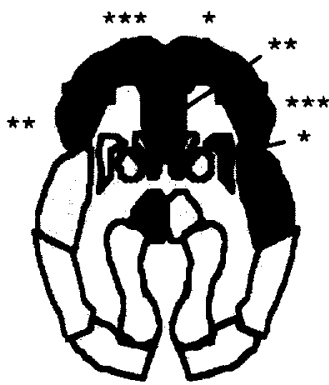

Slice 3

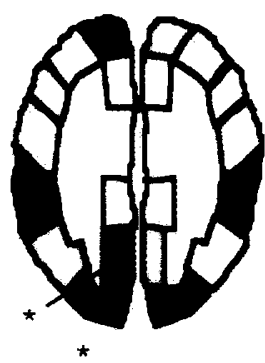

Slice 7

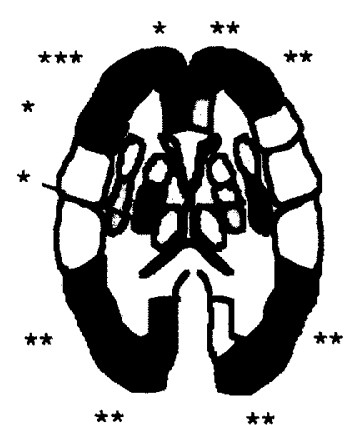

Slice 4

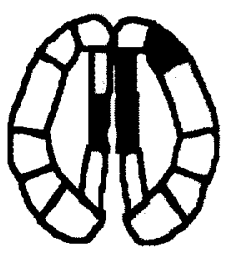

Slice 8

Figure 3. An anatomical representation of correlations between regional metabolic rates and scores of attentional dysfunction in Tourette's patients. Red indicates a positive correlation between these values (i.e., higher regional metabolic rates associated with poorer attentional performance); blue indicates a negative correlation. The magnitude of the correlations is indicated by the degree of stippling: Pearson product-moment correlation coefficients above 0.5 are represented by solid colors; $0.4-0.5$ by dense stippling; $0.3-0.4$ by moderate stippling; $0.2-0.3$ by light stippling; regions with coefficients below 0.2 are uncolored. Significance is indicated by asterisks: ${ }^{\star} p<.05,{ }^{\star} * p<.01,{ }^{\star \star \star} p<.005$. Regions are identified by referring to Figure 2.

bolic rates was therefore transposed and Pearson product-moment correlations calculated between each individual's regional values. A principal component analysis was then applied to the intersubject correlation matrix. As outlined, this procedure, the $Q$-component analysis, makes it possible to detect overall patterns of regional metabolism that can be used to differentiate potential subgroups. If the patient sample were homogeneous, a single factor would result from the analysis. If the sample were heterogeneous, two or more factors would be generated.

The unrotated matrix yielded two factors. All subjects loaded positively on the first, which accounted for the major portion of the overall variance. This is consistent with the expected results of such an analysis, in which the first factor derived from the unrotated matrix generally captures as much of the common variance as possible. The factor scores, however, were not significantly correlated with complex symptom scores $(r=0.28)$ suggesting that this factor may represent a shared pattern that is associated with the diagnosis of TS per se, but is not associated with the severity of behavioral or cognitive symptoms.

The second factor, on the other hand, is orthogonal to the first and will capture as much of the remaining variance as possible in a heterogeneous population. The second factor in this case appears to represent a metabolic pattern with which some TS patients are strongly and others weakly associated, as the factor loadings displayed a much wider dynamic range. The factor scores in this instance were significantly correlated with complex symptom scores $(r=0.71, p=.0009)$, suggesting that this factor represents metabolic pattern associated with behavioral complexity.

Because this factor accounted for a relatively small proportion of the total metabolic variation, however, an oblique rotation of the factor matrix was performed. This process minimizes common variance and will amplify any differences between metabolic subgroups.

Figure 4 illustrates the results of this transformation; taken together, the factor score weights are bimodally distributed and appear to segment the population into two subgroups. Seven subjects (39\%) loaded more positively on the first factor and 11 subjects $(61 \%)$ more positively on the second, the factor weights exceeding 0.5 in each case.

The relative contribution of individual brain regions - the elements of the metabolic patterns that the factors describe - can be determined by examining the factor scores associated with each ROI. The highest re- 
Table 5. Correlations between Regional Glucose Metabolic Rates and Measures of Attentional Dysfunction

\begin{tabular}{|c|c|c|}
\hline \multirow[b]{2}{*}{ Region of Interest } & \multicolumn{2}{|c|}{ Correlation Coefficients } \\
\hline & Left Hemisphere & Right Hemisphere \\
\hline \multicolumn{3}{|l|}{ Subcortical } \\
\hline Midbrain & 0.50 & 0.18 \\
\hline Ventral striatum & -0.18 & 0.08 \\
\hline Putamen & $0.55^{a}$ & 0.39 \\
\hline \multicolumn{3}{|l|}{ Limbic cortical } \\
\hline Medial orbital cortex & $0.66^{\circ}$ & $0.64^{b}$ \\
\hline Lateral orbital cortex & 0.34 & $0.65^{b}$ \\
\hline Opercular orbital cortex & $0.56^{b}$ & $0.76^{d}$ \\
\hline Caudal orbital cortex & $0.62^{c}$ & $0.78^{d}$ \\
\hline Inferior insula & 0.13 & $0.55^{a}$ \\
\hline Parahippocampal region & -0.06 & 0.02 \\
\hline \multicolumn{3}{|l|}{ Frontal motor } \\
\hline Lateral premotor cortex & -0.12 & -0.21 \\
\hline SMA & 0.02 & -0.11 \\
\hline Inferior rolandic cortex & -0.02 & 0.21 \\
\hline Superior rolandic cortex & 0.12 & 0.12 \\
\hline
\end{tabular}

gional scores, the most critical elements, were in each case clustered in the orbitofrontal cortices bilaterally, with the highest scores located in the right hemisphere and in the right inferior insular cortex. Table 6 summarizes the actual metabolic rates derived for each subgroup in the set of regions that had distinguished TS patients and controls. The same pattern is again apparent.

Once subgroups have been identified in this fashion, based solely on the metabolic data, it is possible to see if they differ on other variables. The frequency of individual symptoms was systematically higher in subgroup 2 than in subgroup 1 (Table 7), and complex symptom scores were significantly higher in subgroup 2 as well $(p<.001)$. Both rotated factor scores were in this instance significantly correlated with complex symptom scores (factor $1-r=0.699, p=.0012$; factor $2-r=$ $.723, p=.0007)$.

While $z$-scores for attentional and visuospatial performance were also higher (worse) in subgroup 2 than in subgroup 1, the differences did not attain statistical significance. These trends were also apparent when fac-

Table 6. Normalized Regional Glucose Metabolic Rates in Subgroups 1 and 2

\begin{tabular}{|c|c|c|c|c|}
\hline \multirow[b]{2}{*}{ Region of Interest } & \multicolumn{2}{|c|}{ Left Hemisphere } & \multicolumn{2}{|c|}{ Right Hemisphere } \\
\hline & $\begin{array}{c}\text { Subgroup } 1 \\
(n=7) \\
\text { Mean } \pm \text { SE }\end{array}$ & $\begin{array}{c}\text { Subgroup } 2 \\
(n=11) \\
\text { Mean } \pm \text { SE }\end{array}$ & $\begin{array}{c}\text { Subgroup } 1 \\
(n=7) \\
\text { Mean } \pm \text { SE }\end{array}$ & $\begin{array}{c}\text { Subgroup } 2 \\
(n=11) \\
\text { Mean } \pm S E\end{array}$ \\
\hline \multicolumn{5}{|l|}{ Subcortical } \\
\hline Midbrain & $0.781 \pm 0.025$ & $0.798 \pm 0.024$ & $0.781 \pm 0.027$ & $0.797 \pm 0.027$ \\
\hline Ventral striatum & $1.030 \pm 0.023$ & $1.042 \pm 0.016$ & $1.030 \pm 0.016$ & $1.074 \pm 0.016$ \\
\hline Putamen & $1.100 \pm 0.030$ & $1.173 \pm 0.016^{a}$ & $1.129 \pm 0.021$ & $1.177 \pm 0.023$ \\
\hline \multicolumn{5}{|l|}{ Limbic cortical } \\
\hline Medial orbital cortex & $0.969 \pm 0.029$ & $1.010 \pm 0.021$ & $0.940 \pm 0.026$ & $1.050 \pm 0.025^{b}$ \\
\hline Lateral orbital cortex & $0.888 \pm 0.022$ & $1.057 \pm 0.023^{d}$ & $0.927 \pm 0.039$ & $1.091 \pm 0.031^{c}$ \\
\hline Opercular orbital cortex & $0.915 \pm 0.017$ & $1.003 \pm 0.018^{c}$ & $0.969 \pm 0.016$ & $1.038 \pm 0.024^{c}$ \\
\hline Caudal orbital cortex & $1.049 \pm 0.008$ & $1.125 \pm 0.027^{a}$ & $1.049 \pm 0.008$ & $1.125 \pm 0.027^{a}$ \\
\hline Inferior insula & $1.069 \pm 0.036$ & $1.102 \pm 0.015$ & $1.069 \pm 0.036$ & $1.102 \pm 0.015$ \\
\hline Parahippocampal region & $0.853 \pm 0.026$ & $0.832 \pm 0.011$ & $0.853 \pm 0.026$ & $0.832 \pm 0.011$ \\
\hline \multicolumn{5}{|l|}{ Frontal motor } \\
\hline Lateral premotor cortex & $1.005 \pm 0.016$ & $1.057 \pm 0.019$ & $1.011 \pm 0.018$ & $1.056 \pm 0.020$ \\
\hline SMA & $1.084 \pm 0.030$ & $1.103 \pm 0.024$ & $1.090 \pm 0.031$ & $1.095 \pm 0.022$ \\
\hline Inferior rolandic cortex & $1.025 \pm 0.019$ & $1.023 \pm 0.013$ & $1.075 \pm 0.013$ & $1.045 \pm 0.012$ \\
\hline Superior rolandic cortex & $1.059 \pm 0.016$ & $1.085 \pm 0.025$ & $1.061 \pm 0.014$ & $1.072 \pm 0.022$ \\
\hline
\end{tabular}

\footnotetext{
${ }^{a} p<.05 ;{ }^{h} p<.01 ;{ }^{c} p<.005 ;{ }^{d} p<.001$
} 


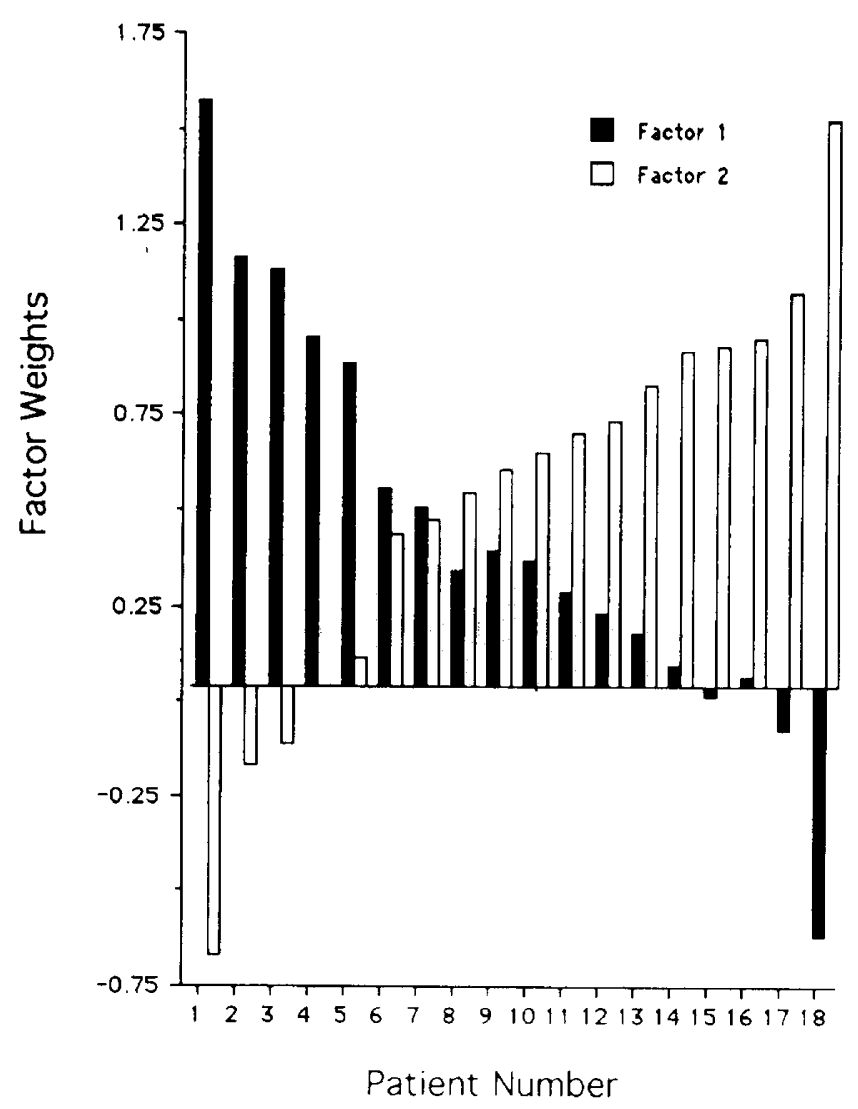

Figure 4. Tourette's subgroups distinguished by Q-component analysis according to methods outlined in the text. Bars represent positive or negative factor weightings for each patient. Solid bars: weights on factor 1; open bars: weights on factor 2 . These values were used to divide the Tourette's patients into two subgroups based solely on patterns of metabolic activity. Patients loading more heavily on factor 1 were designated subgroup $1(n=7)$, those loading more heavily on factor 2 were designated subgroup $2(n=11)$.

tor scores were correlated with the measures of neuropsychological performance (Attention: Factor $1-r=$ $.465, p=.0805$; Factor $2-r=.463, p=.0821$; Visuospatial: Factor $1-r=.419, p=.1204$; Factor $2-r=.408$, $p=.1310$ ).

Table 7. Frequency of Complex Behavioral Symptoms in Subgroups 1 and 2

\begin{tabular}{lcc}
\hline Complex Symptom & Subgroup & Subgroup \\
\hline Self-injurious behavior & $\mathbf{1}$ & $\mathbf{2}$ \\
Impulsivity & 0.00 & 0.27 \\
Echophenomena & 0.14 & 0.27 \\
Coprolalia & 0.00 & 0.36 \\
Obsessive-compulsive behavior & 0.29 & 0.36 \\
Depression & 0.29 & 0.82 \\
Score & 0.29 & 0.64 \\
\end{tabular}

${ }^{a} p<.001$.

\section{Effects of Age, Gender, Drug Treatment}

Age did not correlate with metabolic rates in any of the brain regions that had shown a significant relationship with behavioral or cognitive measures. Furthermore, age was not correlated with behavioral severity or with any of the neuropsychological measures. Nor did gender appear to have a demonstrable effect on the relationships between behavioral or cognitive measures and cerebral metabolic rates. All of the significant correlations outlined persisted when the two females were eliminated from the analysis.

In our previous report, the analysis of normalized cerebral metabolic rates for glucose indicated that recent exposure to neuroactive medications (withdrawal occurring 2-8 weeks prior to the study) did not appear to have a significant effect when TS patients were compared to normal controls. In the present analysis, when metabolic rates in patients recently withdrawn from medications ( $n=6$ ) were directly compared with patients that had been drug free for a year or more or who had never received treatment $(n=12)$, differences were apparent, but these were detected only in the right midbrain $(p<.05)$ and caudal orbital cortices $(p<.01$, left; $p<.05$, right); higher metabolic rates in these regions were observed in patients withdrawn from medications between 2 and 8 weeks prior to the study.

Patients recently withdrawn from medications tended to have higher complex symptom scores (2.6 上 1.8 vs. $1.75 \pm 1.0, p<.15)$ and higher $z$-scores indicating attentional dysfunction $(0.422 \pm 0.70$ vs. $-0.183 \pm$ $0.42, p<.06$ ). Performance IQ scores were significantly lower ( $94 \pm 17$ vs. $113 \pm 8, p<.01)$, and $z$-scores indicating visuospatial dysfunction were higher $(0.673 \pm$ 0.73 vs. $-0.214 \pm 0.36, p<0.01)$ in these patients as well.

\section{Relationships between Behavioral Complexity and Neuropsychological Variables}

The association between behavioral scores and measures of neuropsychological performance was examined directly, independent of their relationship with cerebral metabolism. The primary elements, behavioral scores and functionally discrete neuropsychological variables, were correlated with one another across patients, and a principal components analysis was applied to the resulting correlation matrix.

These features are summarized in the correlation matrix and factor loadings derived from the PCA (Tables 8 and 9). The rotated factor matrix yielded two principal components. The first, a "neuropsychological " factor, contained all independent measures of neuropsychological function. The second, which accounted for approximately half of the total variance, and appeared to capture the variance shared between mea- 
sures of behavioral and cognitive function, consisted only of behavioral complexity and attentional and visuospatial measures.

\section{DISCUSSION}

This work represents an exploratory analysis aimed at generating rather than testing hypotheses. As such, any conclusions that are drawn should be considered tentative. Our results indicate, nevertheless, that certain of the behavioral and cognitive features frequently encountered in TS patients may be linked to functional changes in specific regions of the brain

Our initial report (Braun et al., 1993) indicated that the diagnosis of TS per se appeared to be associated with decreased glucose metabolic rates in the midbrain, ventral limbic-associated regions of the cortex (caudal, medial, and lateral orbitofrontal, insular and parahippocampal cortices), and basal ganglia (particularly the ventral striatum -i.e., nucleus accumbens and ventromedial caudate - and in the putamen). These changes were coupled to increases in metabolic activity in dorsal sensorimotor regions of the brain: supplementary motor area, lateral premotor, and Rolandic cortices. The current results suggest that the presence of associated behavioral and cognitive symptoms may be linked to changes in metabolism in a limited subset of these regions, in particular to alterations in functional activity in the orbitofrontal cortex and basal ganglia.

This pattern was apparent when behavioral symptoms were evaluated: Behavioral severity scores were positively correlated with metabolic rates in all regions of the orbitofrontal cortex and the putamen (Table 3). On the contrary, behavioral scores were not significantly associated with metabolic rates in the midbrain, ventral striatum, inferior insular cortex, parahippocampal gyrus, or the sensorimotor cortices, regions which had, in some cases, more robustly differentiated TS patients from normals.

It should be noted that the summary score was devised in order to deal with a heterogeneous group of patients with a marked overlap of complex behavioral symptoms. In order to truly characterize the metabolic patterns associated with individual symptoms, it will
Table 9. Results of Principal Components Analysis Summarizing Relationships between Behavioral and Neuropsychological Features

\begin{tabular}{lcc}
\hline & Factor 1 & Factor 2 \\
\hline Behavior & 0.027 & 0.968 \\
Attention & 0.767 & 0.485 \\
Visuospatial & 0.768 & 0.428 \\
Memory & 0.897 & 0.075 \\
Executive & 0.665 & 0.065 \\
\hline
\end{tabular}

be necessary to study patients with relatively "pure" clinical presentations (e.g., TS patients in whom obsessive-compulsive symptoms, coprolalia, impulsivity, or self-injurious behavior represent the sole associated behavioral feature). Furthermore, the fact that the behavioral measures used to generate these scores were based on historical interviews and retrospective review of case records rather than the use of standardized instruments could represent a potential limitation of the present study. Nevertheless, our results suggest that, in general, patients with a more complicated neurobehavioral presentation are characterized by elevated orbitofrontal metabolic rates and less robust elevations in the putamen.

Essentially the same pattern was observed when measures of neuropsychological function were examined (Table 4). Performance IQ scores were negatively correlated with metabolic rates in the orbitofrontal cortices: The higher the orbitofrontal metabolic rates, the poorer the subjects' performance. Significant correlations were more robust in the right hemisphere. Verbal IQ scores were only weakly correlated with regional metabolic rates, but when significant correlations were present, they clustered in the orbitofrontal regions. Neither verbal nor performance IQ was coupled to metabolic activity in other limbic or sensorimotor regions of the cortex, basal ganglia, or midbrain.

Of the categorical measures of neuropsychological function, only attention and visuospatial performance, both of which represent elements of the performance $I Q$, were significantly linked to cerebral metabolic activity. Of these, attention was by far the more powerfully connected. Correlations between cerebral meta-

Table 8. Correlation Matrix

\begin{tabular}{lccccc}
\hline & Behavior & Attention & Visuospatial & Memory & Executive \\
\hline Behavior & 1.000 & & & & \\
Attention & 0.482 & 1.000 & & & \\
Visuospatial & 0.457 & 0.667 & 1.000 & & \\
Memory & 0.133 & 0.688 & 0.819 & 1.000 & \\
Executive & 0.064 & 0.552 & 0.329 & 0.315 & 1.000 \\
\hline
\end{tabular}


bolic rates and performance scores (representing neuropsychological dysfunction) were uniformly positive (Table 5). That is, patients with the poorest measures of attentional or visuospatial function had the highest metabolic rates in the orbitofrontal and functionally related inferior insular cortices and similar, although less robust, increases in metabolism in the putamen. Neither measure was significantly correlated with metabolic rates in the midbrain, ventral striatum, parahippocampal gyrus, or sensorimotor cortices.

The $Q$-component analysis, serving as an independent, data-driven approach, provided confirmatory evidence for these findings. Subtypes identified solely on the basis of the regional metabolic data were distinguished by significant differences in metabolism in the orbitofrontal cortices and putamen, but not by metabolism in other regions of interest. Subtypes identified in this fashion could also be differentiated on the basis of behavioral and cognitive measures: As expected, the subgroup with the highest metabolic rates also had the highest indices of behavioral severity and neuropsychological dysfunction, although the latter failed to reach statistical significance.

The relationships between behavioral or cognitive measures and cerebral metabolic rates that we observed are not likely to have resulted from common confounding variables such as age or sex. Age was not correlated with metabolic activity in any of the brain regions that had shown significant relationships with either behavioral or cognitive measures, nor was it correlated with the behavioral or cognitive measures themselves. Because only two of the TS patients were females, they could be excluded from the analysis without significantly reducing the sample size; all relationships detected previously persisted when they were withdrawn.

Although we cannot exclude the possibility that the relationships observed in TS patients could to some degree represent the residual effects of chronic dopamine blockade or exposure to other centrally active medications, this appears relatively unlikely. Although our initial analysis indicated that prior drug exposure had no significant effect on normalized rCMglu when TS patients were compared to controls, the present data suggest that, within this patient group, such exposure appeared to be related to metabolic activity in the caudal orbital cortex, one of the regions in which metabolic rates had correlated with both behavioral and cognitive measures.

This was not a systematic effect however: Recent exposure to neuroactive medications was not associated with metabolism in other regions of interest that were significantly correlated with behavioral features or cognitive performance. If correlations between metabolic activity and these measures were artifactually driven by prior drug exposure, one would expect to see similar relationships between such a history and metabolic rates in medial, lateral, or opercular orbital cortices, inferior insula, or putamen as well. (In addition, prior drug exposure appeared to be related to metabolic rates in the midbrain; and these rates should have been correlated with behavioral or cognitive measures, if such relationships were strictly artifacts of prior drug history.)

On the other hand, the relationship between behavioral or cognitive symptoms and recent exposure to neuroactive drugs might not be causal. That is, the likelihood of having received drug treatment might simply be greater in the more severe cases, which are often associated with more complex behavioral and cognitive features (Bornstein et al. 1991; Randolph et al. 1993). This possibility is supported by the fact that those subjects that had recently been withdrawn from treatment had higher behavioral severity scores: it is unlikely that drug exposure in itself actually worsened behavior, more likely that subjects with more severe behavioral presentations had received treatment. Similarly, recent drug exposure was associated with poorer measures of neuropsychological performance. It is possible, although less likely, that the drugs themselves directly impaired cognitive performance 2 to 8 weeks after withdrawal, more probable that subjects with significant levels of cognitive dysfunction had been treated in the first place.

\section{Functional Characteristics of Identified Regions of Interest}

Orbitofrontal Cortices. The behavioral consequences of lesions of the prefrontal cortex are well documented in the literature. These are often grouped into three distinct syndromes that are in turn associated with lesions in three discrete anatomical regions: the medial, dorsolateral, and orbitofrontal cortices (Cummings 1985). The behavioral and cognitive features associated with TS may be equivalent to the effects seen in patients with orbitofrontal lesions.

The relationship that we observed between metabolic activity in the orbitofrontal cortex and impulsivity (the failure to inhibit socially inappropriate or even selfinjurious behaviors) is consistent with a well-documented body of research. The orbitofrontal cortex appears to play a primary role in behavioral inhibition. Animals with lesions in this region are characterized by poor performance on behavioral tasks (e.g., go/no go, successive discrimination, or reversal) that require suppression of competing or inappropriate responses (Deuel and Mishkin, 1977; Passingham 1972; Rosvald and Mishkin 1961). In animals with lesions of the orbital cortex, spindle bursts, recruiting responses, and other electrophysiological indices of cortical inhibition are abolished (Lindsley et al. 1949; Skinner and Lindslev 1973; Velasco et al. 1968). 
The most striking effects of orbital lesions, however, are observed in the disinhibition of instinctual or emotional behaviors. This is not surprising since it is this region of the prefrontal cortex that has the closest anatomical relationship with the limbic system (Brodal 1981; Fuster 1989; Nauta 1971). Animals with lesions is this region show significant deficits in emotional expression as well as social bonding (Butter et al. 1968, 1970; Kling and Stelkis 1976). Orbital lesions, for example, lower the threshold for emotional reactions, particularly rage induced by hypothalamic stimulation (Sato 1971).

Human subjects with orbitofrontal lesions are characterized by disinhibited and impulsive emotional responses. Patients exhibit socially inappropriate sexual and aggressive behaviors (Blumer and Benson 1975; Hécaen 1964; Jarvie 1954) and may be characterized by a greater degree of risk-taking behavior (Miller 1992). In this context, the apparent association between impulsivity, coprolalia, self-injurious behavior, and orbitofrontal activity observed in our patients appears straightforward.

Symptoms such as echolalia, palilalia, and echopraxia, collectively termed echophenomena, are examples of the more general condition of stimulus boundedness, the excessive control of behavior by external stimuli within the immediate social or physical environment (Stuss and Benson 1986). This condition has been associated with prefrontal cortical dysfunction, and the "environmental dependency syndrome" described by Lhermitte, similarly characterized by an exaggerated dependency on the environment for behavioral cues, has been specifically associated with damage to the medial orbitofrontal cortex (Lhermitte 1983, 1986; Lhermitte et al. 1986; Shallice et al. 1989). The relationship between echophenomena and orbitofrontal metabolism that we observed is consistent with these findings.

The failure to inhibit behaviors routinely triggered by environmental stimuli has also been interpreted as dysfunction of the brain's attentional system (Shallice 1988). Indeed, Shallice suggests that one of the primary roles of the prefrontal cortex is to regulate selective attention, acting as a "supervisory system" and serving to suppress routine responses so that the organism's interaction with the environment can be planned rather than impulsive. The failure of this system should result in significant attentional deficits.

Behaviors observed in animals or human subjects with orbitofrontal lesions support this concept. Animals with lesions in this region are distractible and hyperactive when exposed to a novel environment (Fuster 1989) and, as noted, are characterized by poor performance on behavioral tasks that require the suppression of inappropriate, competing responses. There are numerous clinical descriptions of distractibility in patients with orbitofrontal lesions (Cummings 1985, 1993; Rylander 1939; Stuss and Benson 1986) as well as impairment in what are interpreted as quantitative measures of selective attention (e.g., event-related potentials associated with auditory discrimination (Knight et al, 1981). The relationship between our measures of attentional performance and orbitofrontal metabolic activity is therefore not unexpected.

While visuospatial dysfunction has generally been associated with post-Rolandic, specifically posterior parietal, lesions, there are reports of impairment of visuospatial performance in patients with pathology confined to the prefrontal cortices (Luria 1973; Taylor 1979). Functional alterations in the orbitofrontal regions might in fact exert their effects via interactions with the post-Rolandic cortices. It has been suggested, for example, that the environmental dependency syndrome which has been described might be due to a disruption of the normal balance between functional activity in prefrontal and parietal regions (Lhermitte 1986; Mesulam 1986). Thus, the symptoms of stimulus boundedness and attentional as well as visuospatial dysfunction in our TS patients, while ostensibly related to alterations in orbitofrontal activity, might be due to a disruption of the influence that the orbital cortex normally exerts on posterior parietal mechanisms.

Patients with orbitofrontal lesions may, in addition, experience significant disturbances in mood, ranging from irritability and emotional lability (Cummings 1985) to frank manic or depressive features (Boetz 1974). While orbitofrontal lesions have been more commonly associated with euphoric or hypomanic behaviors rather than depression, there have been reports of depression in orbitofrontal patients, particularly those with right hemisphere orbitofrontal lesions (Graffman et al. 1986). Depression developing in the course of neuroleptic treatment, commonly observed in our group of patients, may represent a unique pathophysiological process superimposed on the functional changes associated with TS. In any case, the relationship between orbital metabolism and dysphoric symptoms in our study is not inconsistent with the appearance of affective symptoms per se in patients with orbitofrontal dysfunction.

Overall, as outlined, patients with orbitofrontal lesions have a unique syndrome: Disinhibited and impulsive, often exhibiting socially inappropriate sexual and aggressive behaviors, they are also distractible, irritable, emotionally labile, and stimulus bound. It is possible that complex behavioral and cognitive features such as impulsivity, coprolalia, self-injurious behavior, echophenomena, and symptoms of affective and attentional dysfunction, which in TS patients appear to be associated with increased orbital metabolic rates, may represent primary elements of the orbitofrontal syndrome. 
While neurosurgical procedures that deafferentiate the orbital gyri have been used to alleviate obsessions and compulsive behaviors in some psychiatric patients (Bridges et al. 1973), it is the clinical PET literature that provides the strongest evidence for an association between obsessive-compulsive disorder (OCD) symptoms and the orbitofrontal cortex. Several PET studies have demonstrated that patients with OCD unassociated with TS have elevated glucose metabolic rates in the orbital gyri (Baxter et al. 1987; Nordahl et al. 1989; Swedo et al. 1989); ${ }^{99 \mathrm{~m} T \mathrm{~T}-\mathrm{HMPAO} \text { SPECT studies have }}$ demonstrated similar increases in orbitofrontal blood flow (Machlin et al. 1991).

Baxter and Guze (1993) have reported the results of FDG PET studies in patients with the concurrent diagnoses of TS and OCD. Metabolic rates in these subjects were compared to those in control subjects and in patients with the diagnosis of OCD alone. All patients with the diagnosis of OCD, whether or not tics were present, had elevated orbitofrontal metabolic rates. Subjects with the diagnosis of TS alone, however, were not included in this study, and a direct comparison with our results is therefore not possible. Another study (George et al. 1993), evaluated cerebral perfusion with HMPAO in TS patients with and without obsessive-compulsive symptoms and reported no differences in normalized frontal (left or right frontalivisual cortical) flow rates. The frontal region of interest utilized in that study, however, was placed at the level of the basal ganglia and therefore did not apparently estimate orbitofrontal perfusion per se.

All of these studies utilized strict DSMIV criteria for the diagnosis of OCD, and these patients' symptoms were therefore likely to have been more severe than those observed in our TS patients. In general, formal measures of obsessive-compulsive features, although elevated in TS patients, are typically rather low when compared with those obtained in patients who meet DSMIV criteria for OCD (Frankel et al. 1986). Nevertheless, it must be noted that in our patients, although the presence of obsessions and compulsions was unequivocally associated with significant elevations in orbital metabolic rates, the rates observed in patients with the highest symptom complexity scores were in general not significantly different from control values.

It should not be assumed, however, that orbital metabolic rates have simply been restored or have "returned to normal" in Tourette's patients with obsessive-compulsive and other complex behavioral or cognitive symptoms. On the contrary, metabolic activity simply estimates synaptic activity - afferent or intrinsic regulation - within a region of interest, and not all synaptic activity is equivalent (Kadekaro et al. 1985; Schwartz et al. 1979; Sokoloff 1992).

The technique, for example, does not discriminate between excitation and inhibition; both are energyrequiring processes, and both produce increases in glucose utilization (Ackerman 1984). Orbitofrontal metabolic rates observed in controls might, for example, represent predominantly inhibitory activity, whereas equivalent rates observed in TS patients with more severe cognitive or behavioral symptoms might reflect abnormal excitatory tone. In addition, the source of afferent inputs cannot be identified. For example, orbitofrontal metabolic activity in control subjects could primarily reflect regulatory input from the dorsomedial thalamus, whereas that observed in TS patients might represent increased input from the amygdala, entorhinal, or cingulate cortices, all of which project to this region as well (Morecraft et al. 1992).

These scenarios are impossible to differentiate using the FDG technique. Our results instead suggest simply that synaptic activity in the orbital frontal cortex is decreased in Tourette's patients without complex behavioral symptoms and that the appearance of these symptoms is associated with increasing synaptic tone within this region. The pattern of correlations with cognitive and behavioral features that we report here suggests that either this synaptic input is dysfunctional or that it represents a compensatory response to disturbed function in other brain regions that may underlie the generation of cognitive and behavioral symptoms.

Other Regions of Interest. The relationship between cognitive symptoms and metabolic rates in the inferior portion of the insula is consistent with the functionalanatomical associations between this region and the orbitofrontal cortices. These cortical regions belong to a subdivision of the paralimbic belt, a ventral paleocortical or "olfactocentric" system that is centered on the insula and from which the contiguous temporal polar and orbital cortices represent neocortical elaborations (Goldberg, 1987; Pandya and Barnes 1987; Sanides 1972). Both insular and orbital cortices have similar connections with other brain regions, and both may serve as a convergence zone for afferents from multimodal association and limbic areas (Mesulam and Mufson 1982a, 1982b; Mufson and Mesulam, 1982; Morecraft et al. 1992). The involvement of the insula with attentional and visuospatial dysfunction in our patients is therefore consistent with the foregoing results.

The apparent relationship between metabolic activity in the putamen and behavioral-cognitive features is somewhat more difficult to interpret, although it is not inconsistent with the report of Baxter and Guze (1993), in which patients with the concurrent diagnoses of TS and OCD showed higher rates of glucose utilization in the putamen than patients with the diagnosis of OCD alone.

Because activity in the orbital and insular cortices 
is significantly related to cognitive and behavioral measures, the region of the basal ganglia that might have been expected to be similarly related would have been the ventral striatum, which is the region to which these cortical regions project. Metabolic activity in the ventral striatum, however, was not significantly associated with either the presence or severity of cognitive-behavioral features.

The putamen, on the other hand, is felt to be the center of a distinct corticostriatal-thalamocortical circuit (Alexander et al. 1986; DeLong 1983), connected to sensorimotor and premotor regions of the neocortex involved in the initiation and execution of movement. Metabolic rates in the sensorimotor cortices were not correlated with cognitive or behavioral measures in our patients. Metabolic rates in the putamen were not only correlated with these measures but also showed a significant association with metabolic rates in the caudal and medial orbitofrontal cortices, the orbital regions with the strongest limbic connections. Interregional correlations such as these are often interpreted as indicating significant functional coupling between areas of the brain. This finding therefore suggests that the normal relationships between dorsal and ventral striatal regions and motor and limbic cortices may be altered in the TS brain. This issue will be addressed in a separate communication (Braun et al. [part III] in preparation).

\section{CONCLUSIONS}

The results presented in the initial paper in this series suggested that relative hypometabolism in inferior frontal, insular, mesial temporal cortices, basal ganglia, and midbrain and that relative hypermetabolism in superior sensorimotor cortices might represent a metabolic diathesis associated with the diagnosis of Tourette's syndrome, that is, these alterations in CMRglu may represent markers for the illness itself.

The results we report here suggest that metabolic activity in a subset of these regions may vary with the severity of behavioral and cognitive features frequently associated with this disorder. This appears to be true whether subtypes are distinguished clinically and assessed with respect to metabolic activity or are distinguished metabolically and evaluated with respect to presence or absence of behavioral and cognitive features. In particular, increases in symptom complexity appear to be associated with increasing, apparently dysfunctional synaptic activity within the medial, lateral, and caudel orbitofrontal cortices.

This observation is consistent with the notion that the complex behavioral and cognitive features commonly associated with the diagnosis of TS-including impulsivity, coprolalia, self-injurious behavior, echo- phenomena, and symptoms of affective and attentional dysfunction - may in fact represent primary elements of the behavioral syndrome typically seen in patients with lesions of the orbitofrontal cortex.

\section{REFERENCES}

Ackerman RF, Finch DM, Babb TL, Engel J, Jr (1984): Increased glucose metabolism during long-duration recurrent inhibition of hippocampal pyramidal cells. J Neurosci 4:251

Alexander GE, DeLong MR, Strick PL (1986): Parallel organization of functionally segregated circuits linking basal ganglia and cortex. Ann Rev Neurosci 9:357-381

Baxter LR, Guze BH (1993): Neuroimaging. In Kurlan R (ed), The Handbook of Tourette Syndrome and Other Tic and Behavioral Disorders. New York, Marcel Dekker, pp 289-304

Baxter LR, Phelps ME, Mazziotta JC, Guze BH, Schwartz JM, Selin CE (1987): Local cerebral glucose metabolic rates in obsessive compulsive disorder: A comparison with rates in unipolar depression and normal controls. Arch Gen Psychiatry 44:211-218

Benton AL, Hamsher K de S (1976): Multilingual Aphasia Examination. Iowa City, University of Iowa Press

Bumer D, Benson DF (1975): Personal changes with frontal and temporal lobe lesions. In Benson DF and Blumer D (eds), Psychiatric Aspects of Neurological Disease. New York, Grune \& Stratton, pp 151-170

Boetz MI (1974): Frontal lobe tumours. In Vinken PJ, Bruyn GW (eds), Handbook of Clinical Neurology, Volume 17: Tumours of the Brain and Skull. Amsterdam, NorthHolland, pp 234-280

Bornstein RA, Baker GB, Bazylewich T, Douglass AB (1991): Tourette syndrome and neuropsychological performance. Acta Psychiatr Scand 84:212-216

Braun AR, Stoetter B, Randolph C, Hsiao JK, Vladar K, Gernet J, Carson RE, Herscovitch P, Chase TN (1993): The functional neuroanatomy of Tourette's syndrome: An FDG-PET study. I. Regional changes in cerebral glucose metabolism differentiating patients and controls. Neuropsychopharmacology 9:277-291

Braun AR, Stoetter B, Randolph C, Hsiao J, Pattee L, Gernert J, Carson RE, Herscovitch P, Chase TN. The functional neuroanatomy of Tourette's syndrome: An FDG PET study. III: Functional coupling of regional cerebral metabolic rates. In Preparation

Bridges PK, Goktepe EO, Maratos J (1973): A comparative review of patients with obsessional neurosis and with depression treated by psychosurgery. Br J Psychiatry 123:667-674

Brodal A (1981): Neurological Anatomy. New York, Oxford University Press

Brooks RA (1982): Alternative formula for glucose utilization using labeled deoxyglucose. J Nucl Med 23:538-539

Brooks RA, Sank VI, Di Chiro G, Friauf WS, Leighton SB (1980): Design of high resolution position emission tomograph: The Neuro-PET. J Comput Assist Tomogr 4:5-13

Butter CM, Mishkin M, Mirsky AF (1968): Emotional re- 
sponses toward humans in monkeys with selective frontal lesions. Physiol Behav 3:213-215

Butter CM, Snyder DR, McDonald J (1970): Effects of orbital frontal lesions on aversive and aggressive behaviors in rhesus monkeys. J Comp Physiol Psychol 72:132-144

Clark C, Carson R, Kessler R, Margolin R, Buchsbaum M, De Lisi L, King C, Cohen R (1985): Alternative statistical models for the examination of clinical positron emission tomography/fluorodeoxyglucose data. J Cereb Blood Flow Metab 5:142-150

Comings DE, Comings BG (1988): Tourette's syndrome and attention deficit disorder. In Cohen DJ, Bruun RD, Leckman JF (eds), Tourette's Syndrome and Tic Disorders: Clinical Understanding and Treatment. New York, Wiley pp 119-135

Cummings JL (1985): Clinical Neuropsychology. Orlando Grune \& Stratton, pp 57-67

Cummings JL (1993): Frontal-Subcortical Circuits and Human Behavior. Arch Neurol 50:873-880

Damasio H, Damasio AR (1989): Lesion Analysis in Neur(1psychology. New York, Oxford University Press

DeLong MR (1983): Cortico-basal ganglia loops. In Massion J, Paillard J, Schultz W, Weisendanger M (eds), Neural Coding of Motor Performance. Experimental Brain Res, suppl 7. Berlin, Springer-Verlag

Deuel R, Mishkin M (1977): Limbic and prefrontal contributions to somesthetic learning in monkeys. Brain Res 132: $521-535$

Duvernoy H (1991): The Human Brain Surface. Three-Dimensional Sectional Anatomy and MRI. New York. Springer-Verlag

Fedio P, Cox CS, Neophytides A, Canal-Frederick G, Chase TN (1979): Neuropsychological profile of Huntington's disease: Patients and those at risk. Adv Neurol 23:239-255

Frankel M. Cummings JL, Robertson MM, Trimble MR, Hill MA, Benson DF (1986): Obsessions and compulsions in Gilles de la Tourette's syndrome. Neurology 36:378-382

Fuster JM (1989): The Prefrontal Cortex, ed 2. New York. Raven

George MS, Trimble MR, Costa DC, Robertson MM, Ring HA, Ell PI (1993): Elevated frontal cerebral blood flow in Gilles de la Tourette syndrome: A ${ }^{99 \mathrm{~m}} \mathrm{Tc}-\mathrm{HMPAO}$ SPECT study. Psvchiatr Res 45:143-151

Gilles de la Tourette G (1885): Etude sur une affection nerveuse caractérisée par de l'incoordination motrice accompagnée d'écholalie et de copralalie. Arch Neurol 9:19-42, $158-200$

Glaze DG, Frost JD Jr, Jankovic J (1983): Sleep in Gilles de la Tourette's syndrome: Disorder of arousal. Neurology $33: 586-592$

Goldberg G (1987): From intent to action: Evolution and function of the premotor systems of the frontal lobe. In Pere:man E (ed), The Frontal Lobes Revisited. New York, IRBN Press, pp 273-306

Gorusch R (1974): Factor Analysis. P'hiladelphia, WB Saunders

Grady CL, Haxby IV, Shapiro MB, Conzalez-Aviles A, Kumar A, Ball MJ, Heston L, Rapoport SI (1990): Subgroups in dementia of the Alzheimer type identified using positron emission tomography. J Veuropsychiatry 2: $373-384$
Gratman I, Vance SC, Weingartner H, Salazar A, Amin D (1986): The effects of lateralized frontal lesions on mood regulation. Brain 109:1127-1148

Hagin RA, Kugler J (1988): School problems associated with Tourette's syndrome. In Cohen DJ, Bruun RD, Leckman JF (eds), Tourette's Syndrome and Tic Disorders: Clinical Understanding and Treatment. New York, Wiley, pp 223-236

Heaton RK (1981): Wisconsin Card Sorting Test. Odessa, FL, Psychological Assessment Resources

Hécaen H (1964): Mental symptoms associated with tumors of the frontal lobe. In Warren JM, Akert K (eds), The Frontal Granular Cortex and Behavior. New York, McGrawHill, pp 335-352

Jarvie HF (1954): Frontal lobe wounds causing disinhibition. J Neurol Neurosurg Psychiatry 17:14-32

Kadekaro M, Crane AM, Sokoloff L (1985): Differential effects of electrical stimulation of sciatic nerve on metabolic activity in spinal cord and dorsal root gangion in the rat. Proc Natl Acad Sci U S A 82:6010-6013

Kling A, Stelkis HD (1976): A neural substrate for affiliative behavior in nonhuman primates. Brain Behav Evol 13: $216-238$

Knight RT, Hillyard SA, Woods DL, Neville HJ (1981): The effects of frontal cortical lesions on event-related potentials during auditory selective attention. Electroencephalography and Clinical Neurophysiology 52:571-582

Kulb B, Whishaw IQ (1990): Fundamentals of Human Neuropsychology, ed 3. New York, WH Freeman

Lezak M (1983): Neuropsychological Assessment, ed 2. Oxford University Press

Lhermitte F (1983): "Utilization behavior" and its relation to lesions of the frontal lobes. Brain 106:237-255

Lhermitte F (1986): Human autonomy and the frontal lobes. Part II: Patient behavior in complex and social situations: The "environmental dependency syndrome." Ann Neurol 19:335-343

Lhermitte F, Pillon B, Serdaru M (1986): Human autonomy and the frontal lobes. Part I: Imitation and utilization behavior: A neuropsychological study of 75 patients. Ann Neurol 19:326-334

Lindsley DB, Bowden JW, Magoun HW (1949): Effect upon the EEG of acute injury to the brain stem activating system. Electroencephalogr Clin Neurol 1:475-486

Luria AR (1973): The Working Brain. An Introduction to Neuropsychology. New York, Basic Books

Machlin SR, Harris GJ, Pearlson DG, Hoehn-Saric R, Jeffrey P, Camargo EE (1991): Elevated medial-frontal cerebral blood flow in obsessive-compulsive patients: A SPECT study. Am J Psychiatry 148:1240-1242

Matsui T, Hirano A (1978): An Atlas of the Human Brain for Computerized Tomography. Tokyo, Igaku-Shoin

Mesulam M-M (1986): Frontal cortex and behavior (editorial). Ann Neurol 19:320-325

Mesulain MM, Mufson EJ (1982a): Insula of the old world monkey. I. Architectonics in the insulo-orbital-temporal component of the paralimbic brain. J Comp Neurol $212: 1-22$

Mesulam MM, Mufson EI (1982b): Insula of the old world 
monkey. IIl: Efferent cortical output and comments on function. J Comp Neurol 212:38-52

Miller LA (1992): Impulsivity, risk-taking, and the ability to synthesize fragmented information after frontal lobectomy. Neuropsychologia 30:69-79

Money J (1976): A standardized road map of direction sense manual. San Rafael, CA, Academic Therapy Publications

Morecraft RJ, Geula C, Mesulam M-M (1992): Cytoarchitecture and neural afferents of orbitofrontal cortex in the brain of the monkey. J Comp Neurol 323:341-358

Mufson EJ, Mesulam MM (1982): Insula of the old world monkey. II: Afferent cortical input and comments on the claustrum. J Comp Neurol 212:23-37

Nauta WJH (1971): The problem of the frontal lobe: A rein terpretation. J Psychiatr Res 8:167-187

Nordahl TE, Benkelfat C, Semple WE, Gross M, King AC Cohen RM (1989): Cerebral glucose metabolic rates in obsessive compulsive disorder. Neuropsychopharmacology $2: 23-28$

Osterrieth PA (1944): Le test de copie d'une figure complèxe: Contribution à l'étude de la perception et de la mémoire. Arch Physiol 30:206-356

Pandya DN, Barnes CL (1987): Architecture and connections of the frontal lobe. In Perecman E (ed), The Frontal Lobes Revisited. New York, IRBN Press, pp 41-72

Passingham RE (1972): Visual discrimination learning after selective prefrontal ablations in monkeys (Macaca mulatta). Neuropsychologia 10:27-39

Randolph C, Hyde TM, Gold JM. Goldberg TE, Weinberger DR (1993). Tourette's syndrome in monozygotic twins. Relationship of tic severity to neuropsychological func tion. Arch Neurol 50:725-728

Ratcliff G (1979): Spatial thought, mental rotation, and the right cerebral hemisphere. Neuropsychol 17:49-54

Rey A (1941): L'examen psychologique dans le cas d'encéphalopathie traumatique. Arch Psychol 28:286-340

Rey A (1986): L'Examen clinique en Psychologie. Paris, Raven

Riddle MA, Hardin MT, Ort SI, Lechman JF, Cohen DJ (1988): Behavioral symptoms in Tourette's syndrome. In Cohen DJ, Bruun RD, Leckman JF (eds), Tourette's Syndrome and Tic Disorders: Clinical Understanding and Treatment. New York, Wiley, pp 151-162

Rosvald HE, and Mishkin M (1961): Non-sensory effects of frontal lesions on discrimination learning and performance. In Delafresnaye JF (ed), Brain Mechanisms and Learning. Oxford, Blackwell, pp 555-576

Rylander G (1939): Personality Changes after Operations on the Frontal Lobes. London, Oxford University Press

Sanides F (1972): Representation in the cerebral cortex and its areal lamination patterns. In Bourne GH (ed). The Structure and Function of Nervous Tissue, vol 5. New York, Academic Press
Sato M (1971): Prefrontal cortex and emotional behaviors. Folia Psychiatr Neurol Jap 25:69-78

Schwartz WJ, Smith CB, Davidsen L, Savaki H, Sokoloff L, Mata M, FInk DJ, Gainer H (1979): Metabolic mapping of functional activity in the hypothalamo-neurohypophysial system of the rat. Science 205:723-725

Shallice T (1988): From Neuropsychology to Mental Structure. Cambridge, Cambridge University Press

Shallice T, Burgess PW, Schon F, Baxter DM (1989): The origins of utilization behavior. Brain 112:1587-1598

Silver A (1988): Intrapsychic processes and adjustment in Tourette's syndrome. In Cohen DJ, Bruun RD, Leckman JF (eds), Tourette's Syndrome and Tic Disorders: Clinical Understanding and Treatment. New York, Wiley, pp 197-206

Skinner JE, Lindsley DB (1973): The nonspecific mediothalamic-frontocortical system: Its influence on electrocortical activity and behavior. In Pribram KH, Luria AR (eds), Psychophysiology of the Frontal Lobes. New York, Academic Press, pp 185-234

Sokoloff L (1992): Relationship between functional activity metabolism in the nervous system: Whether, where and why. In Ingvar D, Lassen N, Raichle M, Friberg L (eds), Brain Work and Energy Metabolism, Proceedings of the Benzon Symposium (Brain work II). Copenhagen, Munksgaad

Stuss DT, Benson DF (1986): The Frontal Lobes. New York, Raven, pp 99-100

Swedo SE, Schapiro MB, Grady CL, Cheslow DL, Leonard HL, Kumar A, Friedland R, Rapoport SI, Rapoport JL (1989): Cerebral glucose metabolism in childhood-onset obsessive-compulsive disorder. Arch Gen Psychiatry 46:518-523

Taylor LB (1979): Psychological assessment of neurosurgical patients. In Rasmussen T, Marino R (eds), Functional Neurosurgery. New York, Raven, pp 165-180

Towbin KE (1988): Obsessive-compulsive symptoms in Tourette's syndrome. In Cohen DJ, Bruun RD, Leckman JF (eds), Tourette's Syndrome and Tic Disorders: Clinical Understanding and Treatment. New York, Wiley, pp 137-149

Velasco M, Skinner JE, Asaro KD, Lindsley DB (1968): Thalamo-cortical systems regulating spindle bursts and recruiting responses: I. Effect of cortical ablations. Electroencephalogr Clin Neurophysiol 25:463-470

Wechsler D (1958): The measurement and appraisal of adult intelligence. New York, Williams \& Wilkins

Wechsler D (1981): Wechsler Adult Intelligence Scale-Revised. New York, The Psychological Corporation

Wechsler D, Sidne CP (1945): Wechsler Memory Scale. New York, The Psychological Corporation

Witkin HA (1950): Individual differences in the ease of perception of embedded figures. Personality 19:1-15 